\title{
AE120167r3 \\ PERFORMANCE-BASED INCENTIVES AND THE BEHAVIOR OF ACCOUNTING ACADEMICS: RESPONDING TO CHANGES
}

\section{INTRODUCTION}

Over the last decade, issues related to scientific production in the field of accounting have emerged as a source of serious concern for academic career aspirants. Promotions at universities are awarded to only those who satisfy the predetermined requirement of publishing a certain number of articles in reputed academic journals (Gendron, 2008; Hopwood, 2008). In Europe, the establishment of such criteria was pioneered by the UK in 1988 with the launch of the RAE (Research Assessment Exercise). More recently, many other European countries-France, Germany, Italy, The Netherlands - and new EU members such as Romania have established country-specific assessment models with similar emphasis on research achievements (Orr, 2004; AIDEA, 2007; Gendron, 2008; Ray, 2008; Albu \& Albu, 2009). A similar practice has been adopted in Spain and publishing papers in prestigious academic journals ${ }^{1}$ has become an important criterion for promotion and tenure, especially since the passing of the 2001 Spanish University Act (Ley Orgánica de Universidades, henceforth SUA). Unlike in the past, when papers published in professional journals were acceptable, the new regulation only considers papers published in indexed academic journals - a change that has completely transformed the Spanish accounting arena. This change is expected to have an important effect in the relationship between accounting research and professional practice. If we consider that accounting research should be closely related to practitioners, helping them to develop and to improve their methods, our question is whether these changes in the accounting research requirements may jeopardize this relationship.

As explained by Meyer and Scott (1983), Institutional Theory is useful in highly institutionalized contexts - such as the Spanish higher education system-with processes of bureaucratic accreditations and a structure based on stable employment, low mobility, and rigid 
wages (where academics achieve the status of civil servants). In such scenarios, the issuance of a new law should be understood as an outcome of a centralized decision-making process promoted within a bureaucratic hierarchy (in this case, the Spanish government), and not of decentralized institutions (such as markets). Using the Institutional Theory approach, we attempt to analyze the long-term effect of the SUA on the production of publications by Spanish accounting scholars. In the framework of this theory, we postulate that institutional isomorphism will increasingly underpin common research activity and research orientation, emulating other countries where similar processes have taken place.

Institutional Theory (see Meyer \& Rowan, 1977; DiMaggio \& Powell 1983, 1991; and North, 1990) considers institutions as a set of norms, schemes, and restrictive rules (formal and informal) that exert some impact through their structure of incentives and opportunities. It provides an alternative sociological-based perspective to the economic-based explanations of academic accounting research development (Watts \& Zimmerman, 1978), and states that organizational fields may evolve from diversity to homogeneity by means of isomorphism. DiMaggio and Powell (1983) identify two general types of isomorphism: competitive and institutional. In this regard, while competitive isomorphism is mostly driven by the pursuit of efficiency, institutional isomorphism is mediated by the ability of one or more groups or entities to accumulate power to achieve legitimacy. Efficiency no longer dominates and the institutional process becomes political. Then, the institutionalized practices and norms become generally accepted, without serious questioning of their relevance in particular settings. The time required to establish these institutionalized practices will depend on the stability of the entity's environment and the governance and regulatory context of the field.

Institutional Theory has been used in several studies analyzing higher education systems and the evolution of academic accounting research. Etherington and Richardson (1994) explore patterns of responses to institutional pressures affecting accounting education, and Leicht and Fennell (2008) study the interaction between administrative and academic careers in the US higher 
education system. Tuttle and Dillard (2007) build upon institutional theory to identify the key factors explaining changes in US accounting research and also to promote remedies for the reduction of research diversity. Based on the idea that the institutional framework constrains the forces acting on members of organizational fields, and that it complements the economic-based explanations of accounting research development (Watts \& Zimmerman, 1978) these authors show how institutional isomorphism has led to narrower approaches and perspectives.

With a focus on empirical work, we analyze five specific aspects of the research published by Spanish accounting academics for the period 1996-2005: (a) the geographical reach (national or international), (b) the orientation of the articles (academic or professional), (c) the research methods (empirical or non-empirical), (d) the topics discussed in the articles, and (e) the quality of the journal in which these articles have been published. While our empirical analysis confirms the expected increase in the number and quality of academic articles, aligned with Moed (2008) and Bentley and Kyvic (2012), our results do not completely support the isomorphism postulate because the range of topics did not narrow in that period. It also highlights some unexpected and undesirable changes affecting the number of professional articles. Although this was clearly not the immediate intent of the SUA, the fact remains that the transmission of knowledge through professional journals has certainly been curtailed. We believe that these results are linked to the discontinuation of publishing activities by a significant number of accounting academics.

In summary, while young academics, with non-permanent contracts, oriented their research to what was considered mainstream in the most relevant academic accounting journals, a substantial drop was seen in the research activity of stable professors. Additionally, academics stopped writing articles addressed to practitioners, which significantly reduced the transfer of knowledge from universities to professionals.

Although there is a vast literature explaining the effects of research assessment on academics, the Spanish case is of particular interest to consider the switch from professional to academic 
journals and its implications. Before the SUA papers published in journals mainly addressed to accounting practitioners were considered for the promotion of academics, as, needless to say, were contributions to academic journals. As a result, before the SUA the majority of papers in professional journals were written by academics, which contributed to the dissemination of knowledge to accounting practitioners such as, for example, explaining accounting of complex transactions or new principles derived from the adaptation to IFRS. With the new situation, in which only papers in academic journals are evaluated for promotion, the participation of academics in the diffusion of accounting issues to practitioners through professional journals has fallen substantially. Papers in these journals are now written by practitioners or by stable professors without tenure pressures to publish academic research in indexed journals. The participation of new members of academia in professional journals is now very scarce.

Apart from offering insights into the Spanish experience, this study is of general interest as it shows how academics modify their strategies and behavior in response to changes in their incentives, and contributes to the existing literature on the contemporary situation in the field of accounting research (e.g., Bricker, 1989; Chung, Pak \& Cox, 1992; Merino, 1993; Reiter \& Williams, 2002; Larrinaga 2005; Napier, 2006; Hopwood, 2008; or Sangster, 2011).

The rest of the paper is organized as follows: the first section presents an overview of Spanish accounting research. This is followed by hypotheses on the effects of the SUA on accounting research. The empirical section presents descriptive statistics concerning the database, which is followed by results, hypotheses tests, conclusions, and implications.

\section{BACKGROUND AND HYPOTHESES}

\subsection{THE SPANISH CONTEXT}

In order to understand the evolution of academic accounting research, it is necessary to consider the Spanish higher education context. Most universities in Spain are public, and academic careers are regulated by different laws. Between 1983 and 2001, Spanish universities were 
regulated by the University Reform Act (URA, Ley de Reforma Universitaria). During the enforcement of the URA, economic growth in Spain was converging with that of the western European countries, and educating the increasing number of undergraduate students was the chief priority of the Spanish university system. This task was explicitly outlined by the university regulatory body (García-Benau \& Laínez-Gadea, 2004).

During the 1990s, several measures were adopted to promote research in Spanish universities (Montesinos, 1998; Garcia-Benau \& Laínez-Gadea, 2004). These measures included increased allocation of funds to research projects (supporting the operating expenses of the research activity and promoting the development of international links) and the introduction of a longterm research assessment plan (which includes an incentive award for those professors obtaining a positive assessment for their research on a six-year basis). However, these actions had a scant effect on remuneration. Moreover, this assessment was non-mandatory, and only conferred merit in terms of enhanced personal and university reputation ${ }^{2}$.

Those measures, together with the prerequisites for an academic career defined by the new regulation, led to an increase in Spanish scientific production (in terms of the number of academic papers presented at conferences and/or published in academic journals). As a result, between 1991 and 1999 Spain was second only to the UK in the number of submissions to The European Accounting Review, reflecting the improvement in the productivity of academic papers during these years (Loft, Jorissen \& Walton, 1999).

By 2001, when the SUA was approved, demographic changes had led to a decrease in the number of undergraduate students and fewer teaching hours, and research had acquired more importance. Under the preceding regulation, each university controlled access to a permanent teaching position and the promotions of its scholars. Prerequisites at the time included having a $\mathrm{PhD}$ and a minimum number of published academic or professional papers, though the number was not specified in any written regulation. Further, the selection process was largely endogamous because the university could appoint two of the five members constituting the 
candidate evaluation committee. As a result, in the vast majority of the cases the local candidate was appointedto the permanent teaching position. Within this framework, young and untenured teachers had few incentives to conduct research. For tenured teachers, the incentives were based on the long-term research assessment (with minimum financial benefit, as mentioned earlier) or upgrading to the category of chair, for which most candidates were assessed by their home universities.

In the post-SUA scenario, permanent positions became accessible only to scholars who were positively evaluated by the National Agency for the Assessment of the Quality and Accreditation (ANECA), and, according to the new evaluation criteria, research received more weight than teaching activities (50\% for research and $40 \%$ for teaching). The SUA mandated that research quality should be assessed according to international standards, requiring eight publications in indexed journals with an academic readership to achieve the maximum score in the research assessment. After receiving the positive assessment, universities could select their permanent staff from among those having favorable evaluations. Access to higher positions (the main route to higher salaries) also followed a similar process. According to the SUA, research was now a right and an obligation of Spanish scholars (Art. 40). As a consequence, the SUA has substantially incentivized Spanish research, guiding it toward recognition in international, indexed academic journals. However, the strategic scope of this legal institutional change is yet to be explored.

One of the questions that we expect to arise from our research concerns the consequences for the relationship between accounting research and professional practice if academics are now bound to publish in international academic journals. The situation previous to the SUA was different in that during the 1990s many Spanish accounting academics published professional papers that contributed to the understanding and dissemination of accounting standards (the first mandatory accounting standards in Spain were issued in 1991, in response to the European harmonization process). Although these articles were less valuable in securing promotions, 
publishing in professional journals, ahead of academic ones, was a viable option for accounting scholars, as journal acceptance was easier to obtain. A change can be expected based on the fact that professional journals are generally not indexed and, therefore, are no longer considered in promotion processes.

\subsection{HYPOTHESES DEVELOPMENT}

Several concepts and theories have been developed to precisely analyze and identify individual motivations to publish. A relevant concept to our study - and central to Institutional Theory — is isomorphism, which refers to imitation under similar conditions. DiMaggio and Powell (1983) defined two mechanisms of isomorphic change that explain the behavior of individuals: competitive and institutional isomorphism. Competitive pressure manifests as motivation to publish when academics operating in a market attempt to maximize utility in terms of salary and reputation through publications. Universities then compete for the best scholars by offering them better salaries and means to carry out their research. Moizer (2009) identifies this as an economic incentive to publish, in addition to others such as a decrease in the teaching workload or receiving research funds or awards. In Spain, however, it is difficult to consider competitive pressures as the main driver toward publishing given that before the SUA, research was not a very important criterion for tenure and promotion. Salaries in the Spanish university system are exactly the same for each professor category, and tenure and promotion are governed by external agencies, while there is no established job market for academics in the accounting arena.

Institutional pressures play a more important role in Spanish academia. They can be classified into three categories: coercive, mimetic, and normative (DiMaggio \& Powell, 1983). The coercive mechanism refers to the pressures to conform to social expectations and the pressures of dominant organizations that control resources. Examples of coercive mechanisms relevant to this investigation include stability, securing better positions, or acquiring research funds. Thus, under the coercive mechanism, motivation to publish is a response to external pressures, such as 
research assessment criteria, imposed by employing institutions and individual researchers (Cheung 2008) or an attempt to gain legitimacy among target audiences (Luukonen, 1992).

The mimetic mechanism refers to imitation as a response to uncertainty. In other words, individuals find it prudent to adopt strategies that have yielded desirable results for others. Evidence of this trend can be found in the changes seen in academics' CVs over time. Researchers tend to imitate their colleagues to gain recognition, and the legitimacy incentive explains mimetic pressures (Luukonen, 1992; Cheung 2008).

Finally, the normative isomorphism stems from professionalization (DiMaggio \& Powell, 1983; Tuttle \& Dillard, 2007), which entails the establishment of common training regimes, academic associations and other socializing mechanisms within the field. Evidence of normative isomorphism in accounting research can be found in generally accepted rankings, acknowledged centers of competence or generally accepted research norms and values that may lead to closer research behaviors. Each of these three mechanisms has an individual effect, although they can operate simultaneously and their effects can be difficult to distinguish.

The SUA introduced coercive mechanisms into the Spanish university system through accreditation and by raising the importance of research. Thus, coercive mechanisms were responsible for driving the number and quality of papers, reinforcing mimetic and normative institutional forces. Prior literature refers to similar experiences in other countries such as Austria, UK, Australia or the Low Countries (see, for example, Shore \& Wright, 2000, Sangster, 2011, Nedeva et al., 2012, Hussain, 2012; and Decramer et al., 2012). Some of these authors discuss the introduction of "league tables" (coercive and normative mechanisms again) to determine tenures and promotions in the university system, affecting professors' behavior and, to some extent, generating undesirable consequences.

Considering the above reasoning and taking into account similar experiences ${ }^{3}$ in other countries, we formulate the following hypotheses, considering not only coercive but also mimetic and normative pressures: 


\section{$H_{1}$ : The institutional forces introduced by the new regulation have led to an increase in the number of publications. \\ $\mathrm{H}_{2}$ : The institutional forces introduced by the new regulation have led to an increase in the quality of publications.}

However some literature adopts an alternative point of view that provides arguments to reject $\mathrm{H}_{1}$ and $\mathrm{H}_{2}$. Indeed, in some cases changes lead to perverse incentives that influence academics' behavior. Hopwood (2007) shows that a high percentage of accounting scholars, more than scholars from other disciplines, cease research activity once they secure a stable job. Once tenured, they tend to pursue alternative activities that include increased teaching in postgraduate courses or offering consultancy services, thus reducing academic research to a means of career progression rather than the end in itself. Promotion mechanisms target incentives at tenured teachers, motivating them to conduct more research with a view to increasing their opportunities to reach higher positions.

Our study also attempts to identify certain patterns in publication before and after the SUA in terms of the journal orientation (academic vs. professional; national vs. international), the research methodology used in the studies (empirical vs. non-empirical) and their topics. Mimetic pressures alone could explain isomorphic changes if the majority of the academics sought to publish the same kind of articles (in orientation, topics, and methodology). However, coercion can also influence this behavior because accreditation agencies impose conditions to facilitate evaluation, and regulations require publications in indexed and recognized journals only. Hence, Mizruchi and Fein (1999) argue that mimetic forces have received disproportionate attention over coercive and normative ones and that the latter can be more important in a nonUS environment.

In the Spanish context, we can attribute additional effects to coercive pressures. Writing in a foreign language can act as a major barrier to publication, leading to a preliminary increase in publications in national indexed academic journals. However, given that international academic journals are the most desirable targets, we can expect a gradual increase in the number of 
publications in these journals, since most professional journals are not indexed, and Spanish academic accounting journals are few in number (García-Benau \& Laínez-Gadea, 2004). This trend toward internationalization has been confirmed by Kyvik (2003) in his study of academics' behaviors in Norway. On the basis of the above findings, we define two hypotheses about the change in the preferences of Spanish accounting researchers:

$H_{3}$ : The institutional forces introduced by the new regulation have led to a shift in the orientation of articles to suit academic rather than professional journals.

$H_{4}$ : The institutional forces introduced by the new regulation have led to a shift in the orientation of articles to suit international rather than national journals.

From the research orientation point of view, changes in the research methodology after the SUA can be attributed to the new requirements that favored indexed journals and the fact that most indexed journals in the accounting field focus on empirical studies. The initial situation in Spain was the reverse, with few studies adopting a positive approach (Montesinos, 1998) as most of the research was aimed at professionals and therefore normative.

Other studies signal the growing importance of empirical methodologies, especially those centered on quantitative data, as opposed to non-empirical methodologies. The vast majority of Spanish accounting scholars now use a positive-methodological approach, to the detriment of behavioral or social issues and case studies (García-Benau \& Laínez-Gadea, 2004). Field studies are seen as less verifiable and more difficult to assess than quantitative methodologies owing to data availability problems (Hopwood, 2007). The SUA does not adopt direct or coercive mechanisms to promote a shift from non-empirical to empirical methodologies; however, it does endorse publication in indexed journals. Moreover, because most indexed publications are dominated by empirical methodologies (oriented toward the use of quantitative analysis), mimetic and normative pressures seem to influence the shift in research methodologies. Hence, we formulate the following hypothesis:

$H_{5}:$ The mimetic and normative mechanisms introduced by the new regulation have led to a shift from non-empirical to empirical studies, mainly based on quantitative analysis. 
In this paper, isomorphism has been used to explain the evolution of topics in accounting research. In a similar study, Hopwood (2008) suggests that the heightened pressure to publish leads academics to concentrate on select mainstream topics as they improve their chances of publication. In a bid to avoid risks, researchers seek to study well-established areas of investigation. Lee (2006) also shows that the RAE has led to a decline in unexplored areas of research because scholars seek to publish in well-cited fields. Newman (2009) confirms that the RAE is responsible for closing established avenues of research that are perceived as failures under the evaluation system. Clearly, new fields of research that lack a history of citations are viewed as problematic. New incentives introduced by the SUA have possibly precipitated the concentration of research in areas that enhance academics' probabilities of being published. If research is considered as a means to further one's career, accounting research will, naturally, turn cautious and conservative (Hopwood 2007), thereby reducing the diversity of the research topics (Tuttle \& Dillard, 2007). The above discussion indicates that isomorphic forces rooted in mimetic and normative mechanisms play a stronger role than coercive ones (as there is no obligation to change research topics). Thus, we formulate the following hypothesis:

\footnotetext{
$H_{6}:$ The mimetic and normative mechanisms introduced by the new regulation have narrowed the spectrum of research topics.
}

\section{DATA AND OPERATIONALIZATION OF VARIABLES}

To investigate the aforementioned research hypotheses, we compiled a database comprising details of scientific accounting papers authored by Spanish academics from 1996 to 2005 (subsequent expansions of the database demonstrated that the results were temporally consistent, both before and after these years). This time period covers the situation before the SUA to control for research-related measures taken during the previous years (research assessment, increased grants, and financed projects) and the immediate years after the new regulation. While we would have liked to include books and working papers, we were limited to 
articles published in journals because reliable information was not available to assess the impact factor of books and working papers (in line with Sangster, 2011, we do believe that books may also include relevant research and that, therefore, their exclusion is an important limitation of our analysis).

Our basic unit of analysis is the Spanish accounting academic who, between 1996 and 2005, published at least one article in a journal included in a Spanish database. We used the IN-RECS database, the most complete and well-known Spanish source for ranking journals in the social sciences ${ }^{4}$. This database collects all the indexed and non-indexed Spanish journals, both academic and professional. For each academic listed in this database we identified all his/her papers in Spanish and non-Spanish journals. This database did not provide information before 1996, and at the time of collecting the data we did not have any complete information for years after 2005 .

A total of 403 academics satisfied the abovementioned requirement (Moya \& Prior, 2008). The database was exclusively for Spanish publications; data on international publications by Spanish academics in the accounting field was obtained by individually searching for their publications on Google Scholar. By combining the information from these two databases and controlling for reiterations, we obtained a total of 1,245 articles.

The first classification criterion was applied as a binary variable: articles were classified as academic $(A C A)$ or professional $(P R O)$ according to the orientation of the journal in which they were published. Journal orientation was determined from the "aims and scope" section, and if that proved inconclusive, double peer review was used as a criterion, i.e., peer-reviewed journals were classified as academic. Journals aimed at helping accountants or business professionals (or public administration professionals) with their work were treated as professional. These journals usually assume a normative stance in addition to having an informative or educational mission. Articles in professional journals typically adopt a positive or descriptive approach, but the analysis is rarely complex. On the other hand, academic 
journals mainly target the research community and seek to explain reality using a consistent theoretical framework, sometimes with the help of complex analytical or empirical methods or concepts.

Our classification into academic and professional papers is an ad-hoc classification and it is not based on any index. This is because none of the indexes has a wide coverage, considering all the journals that have a positive approach, directed mainly to academics, and that have been used in Spain for promotion purposes. For example, the Spanish regulation specifically mentions three indexes to assess the research, among others: SSCI, Econlit and Latindex. None of these is useful for our research for several reasons. The SSCI only includes $2 \%$ of the papers we analyzed, with notable absences. For example, in 2005 neither the European Accounting Review (2\% of the papers analyzed) nor the Revista Española de Financiación y Contabilidad (REFC, $14 \%$ of the papers) were considered in this index, and both journals have a clear academic orientation and have been used in assessments for promotion purposes in Spain. Moreover, these and other journals that we considered as academic without belonging to any index have recently been included in the SSCI. The same situation occurs with Econlit (only 8\% of our papers are included in this index) and Scopus (17\% of the papers).

Taking the three abovementioned indexes together, only $24 \%$ of our analyzed publications are considered, although we are aware that Spanish academic production is clearly higher (REFC was not found in any of these indexes, for example). In contrast, most of papers in our study (79\%) are indexed in Latindex. This index captures both professional and academic journals and, in the end, has very little importance to promotion. Thus, when making our academic/professional classification, we considered academic journals that, although not included in any index, have a clear academic orientation and are considered in promotion processes.

The second classification concerned topics and research methods. For topics, we used Sundem's (1987) seminal classification and extended it on the basis of the definition provided by the 31 st 
Annual Congress of the European Accounting Association $(E A A)^{5}$. We then adapted the EAA classification to the Spanish context and included a miscellaneous category for non-accounting papers $(N A C)$. Each one of the 1,245 articles was classified into one of the categories. To avoid bias introduced by a possible lack of consistency, all the articles were categorized by one person $^{6}$. Regular meetings were held to comment on issues and resolve methodological problems. For instance, if a paper seemed to belong to two or more categories, where possible it was classified according to the main topic it reflected or in accordance with the aims and scope of the journal in which it had been published. Assigning a paper that could have been included in several categories to only one category is a limitation of this study. A further limitation is that a wide spectrum of topics is included in the OTHER category. However, it represents only $5 \%$ of the total papers. Table 1 lists all the categories and provides a brief description of each one.

[Table 1 around here]

For categories of research methods, we again used Sundem's work but eliminated "capital markets" and "empirical methods" as categories because we considered the former to be a topic and the latter was accounted for in our previous classification of papers into empirical and nonempirical. We also extended new methodologies for research. Table 2 summarizes the categories and includes details of the research methods.

[Table 2 around here]

As a third criterion, we considered each article's national or international reach. Papers published in journals edited in Spain were considered national whereas papers appearing in journals edited elsewhere were considered international. All non-Spanish papers (8\%) are academic and $60 \%$ of them take an empirical quantitative approach. 


\section{DESCRIPTIVE STATISTICS, RESULTS, AND DISCUSSION}

\subsection{EFFECTS OF THE NEW REGULATION ON RESEARCH QUANTITY AND QUALITY}

In Table 3 we analyze the evolution of the number of papers and their composition, distinguishing between academic and professional papers, and considering Spanish and nonSpanish journals. With regard to the quantity, Table 3 Panel A shows that the number of total papers increased until 2003, from a minimum of 90 papers in 1998 to a maximum of 175 in 2003. In 2004 and 2005 the trend reversed, and by 2005 the number of papers had decreased to 105, values similar to those found before 2000. These results do not support $\mathrm{H}_{1}$ and seem to be partially aligned with the findings of Oster and Hammermesh (1998) and Hopwood (2007) in other countries: for tenured Spanish accounting academics research is not an end in itself, as the incentives they have to publish are lower.

[Table 3 around here]

To what extent is the reduction in the number of articles influenced by a more selective behavior on the part of academics, i.e., writing fewer articles but of greater quality that stand higher chances of being published in more reputed journals? To explain this trend, we obtained the impact factor index for each publication using Harzing's Publish or Perish $(P o P)$ tool $^{7}$. The PoP database is highly suited to our study, since most of the analyzed papers are published in Spanish, and, to our knowledge, there is no better way to homogenize the impact factors of papers written in different languages than $P o P$. The citation metric we employ is the ageweighted citation rate $(A W C R)$, an index that measures the number of citations of a paper adjusted by its age (Bihui, 2007). We chose $P o P$ as it has been found to have broader coverage of accounting citations than other databases, such as Scopus or Web of Science (Bar-Ilan, 2008; Rosenstreich and Wooliscroft, 2009). As pointed out above, very few of the publications considered are included in the abovementioned indexes, which impedes the use of specific impact factors. Moreover, there are methodological differences to calculate their impact depending on the index considered. However, we are aware of the limitations of considering the 
number of citations as a measure of quality (see a complete discussion on this issue in Walter et al., 2003), but in our case study it is the only way to homogenize the level of quality of the analyzed papers.

Papers that do not appear in $P o P$ were considered as articles without citations because, in most cases, they are published in Spanish journals with low impact factor ratings. In our sample, $68 \%$ of the analyzed papers did not have citations and belonged mainly to Spanish (97\%) and professional journals (54\%). There are high correlations between papers with a positive $A W C R$ index and academic papers (40\%), and positive $A W C R$ index papers and non-Spanish journals (75\%) (significant $\chi^{2}$ in both cases). The advantage of using the AWCR index instead of the academic/professional classification is that, as a proxy, it is the best overall measure of quality that we can find for our sample of 1,245 articles.

Table 4 illustrates this situation. Panel A shows papers with positive AWCR divided into quartiles. Quartile 1 represents papers with the lowest impact, while quartile 4 represents those with the highest impact. Papers in quartile 1 drop to zero after 2001 (the first year of the SUA), quartile 2 also exhibits a declining trend from 2003 to 2005, when it drops to zero, and quartile 3 declines in importance from 2000. Meanwhile, papers in quartile 4 rise from 2000 onward. From the table, it is clear that the articles have improved in terms of impact, especially since 2001. Analysis of the data two years before and after 2002 (the SUA was approved in December 2001) shows that changes between these two periods are significant for quartiles 1 (decrease in the number of papers) and 4 (increase in the number of papers) but not for quartiles 2 and 3.

[Table 4 around here]

In Panel B of Table 4, we compare information between the pre- and post-SUA periods in terms of the total number of papers, the total impact measured by the sum of $A W C R$, and the impact factor by paper. While the number of papers is approximately the same, their impact increases in a statistically significant manner, as does the impact per paper. Thus, this evidence supports $\mathrm{H}_{2}$. 
In the second part of Panel B in Table 4, we compared the number of authors, total papers, and papers by author in the pre- and post-SUA periods. While the number of authors publishing academic papers increased, the number of those publishing professional papers decreased. Moreover, since the growth rate of academic papers exceeds the growth rate of authors, the number of academic papers per author, which can be interpreted as productivity, increased from 1.30 to 1.35 between the two periods. In contrast, the productivity of authors publishing professional papers decreased from 1.30 (similar to the pre-SUA productivity for academic papers) to 1.13, a higher drop than the increase in academic papers. The number of professional papers fell to a number less than the number of authors publishing these papers. Thus, a dual path explaining the evolution of academic and professional articles is evident.

\subsection{ORIENTATION OF ARTICLES}

Our classification results, presented in Table 3, indicate a significant shift in importance from professional to academic papers. As expected, Spanish accounting researchers responded to the SUA by veering away from professional toward academic research ${ }^{8}$.

As shown in Table 3 Panel A, in 1996 only $45 \%$ of the papers were academic compared to $70 \%$ in 2005. The distribution of the total number of papers indicates that 2003 was the most productive year, and in this year the trend toward academic papers consolidated, because it is the first year in which the percentage of academic papers was higher than the percentage of professional papers, which increased until 2005, showing a positive time trend. However, 2001 was the most productive year for professional papers. Production of professional papers subsequently witnessed a gradual decline.

Values of Pearson $\chi^{2}$ given in Table 3 Panel B indicate whether there are statistically significant differences in the percentage of professional and academic papers between two years. We only show the results for the years where these differences are significant. To interpret the results we can consider, for instance, the Pearson $\chi^{2}$ value of 11.2 between the years 1996 and 2003 (significant at a 0.01 level). This value was calculated by comparing the percentage of papers 
(academic and professional) published during these two years, shown in Table 3 Panel A. Thus, according to Table 3 Panel A, in 1996, 45\% of papers were academic and 55\% were professional, and in 2003, 66\% were academic and 34\% were professional. Table 3 Panel B confirms that these differences are statistically significant.

Panel B in Table 3 indicates that the difference between academic and professional papers was first found to be significant in 2003. However, statistically, 2003 was not significantly different from 2004 or 2005 (we do not show non-significant values in Panel B Table 3). Thus, we can confirm that in 2003, two years after the approval of the SUA, the orientation of papers significantly changed from professional to academic, supporting $\mathrm{H}_{3}$. This trend was further consolidated in the subsequent years. Considering that the period between submission and publication in many academic journals is one or two years, this can suggest that the change occurs around 2001, the year the SUA was approved.

Table 3 Panel C shows the percentage of papers published in Spanish and non-Spanish journals. From this table, we can determine that the number of papers appearing in non-Spanish journals increased significantly over time (from $2 \%$ in 1996 to $15 \%$ in 2005). Table 3 Panel D is constructed in a similar manner to Panel B. From Panel D, we can conclude that 2004 was the first year when the difference between Spanish and non-Spanish journals was significant and temporally consistent. These findings, however, are not as conclusive as those seen in Panel B. Panel D suggests that in 2004, two years after the introduction of the law, the preferences of Spanish accounting researchers led to a significant difference in papers published in Spanish and in non-Spanish journals. Taking this finding into account, together with the analysis of the percentage of academic papers, it can be seen that in a first stage researchers attempt to publish in Spanish academic journals, and in a second phase they shift toward non-Spanish academic journals, where the competition and standards are higher.

Although the percentage of papers published in non-Spanish journals is comparatively low ( $15 \%$ in 2005 vs. $2 \%$ in 1996), the trend is extremely positive and highly significant, as shown 
by the Pearson $\chi^{2}$ value of the Panel C in Table 3 or by a Spearman's rank correlation (rho $=$ +0.963 with p-value < 0.01). Thus, our findings provide support for $\mathrm{H}_{4}$.

\subsection{RESEARCH METHODS}

As shown in Table 5 Panels A and B, we first classified our methods as empirical and nonempirical.

[Table 5 around here]

Panel A in Table 5 shows that papers with empirical methods increased from 26\% in 1996 to $50 \%$ in 2005. Panel B in Table 5 shows that while there were some significant differences between 2003 and the previous years, the overall differences were significant only in 2004 . Thus, we can conclude that differences between empirical and non-empirical methods were moderately significant in 2003, and the changes consolidated in 2004.

To investigate the research method hypothesis, we examine Table 5 Panels $\mathrm{C}$ and $\mathrm{D}$, which include details of the main research methods used by Spanish scholars, and research trends over time. On average, the most frequently used research method is theoretical $(41 \%)$, followed by statistical (28\%) and deductive (20\%) methods. These results are consistent with our data as most of the papers published during 1996-2005 were submitted to Spanish journals that traditionally publish professional works employing theoretical and deductive methods (nonempirical). However, an evident trend over time is the drop in the use of theoretical and deductive methods and a spike in the use of statistical and other methods (mainly empirical, as seen in Panel A). Table 5 Panel D indicates that the changes in research methods became significant in 2002 and were consolidated in $2004^{9}$. Thus, $\mathrm{H}_{5}$ is supported.

In Table 6 we present additional information about the interaction between different subsets of journals and their categorization in research methods. For academic papers the change from non-empirical to empirical is clear in the analyzed period (49\% in 1996 vs. $73 \%$ in 2005), especially in the last two years. Of the empirical methods, statistical analysis is the most 
widespread (73\% of the total sample), and we cannot detect any consistent trend. If we consider non-empirical academic papers, the theoretical approach is the most important (78\% of total papers), with no clear trend. In sum, in the case of academic papers it seems that the empirical approach, based on statistical data, is the most successful. The most important change appears in 2004, when participation in non-Spanish academic journals increased, which requires a more empirical approach.

The main approach of professional papers is non-empirical (85\% of the total sample), although until 2004 we detect a slight trend toward empirical treatment that changes radically in 2005 . In their empirical orientation, the statistical approach seems to decline more than others, such as case studies. Non-empirical orientation for professional papers is centered on theoretical development, which increased except in 2005, compared with the deductive approach.

\subsection{TOPICS BY ORIENTATION AND RESEARCH METHODS}

In this section we examine papers distributed by year and topics. As there were no significant yearly differences, we assessed mid-term trends. In the first two columns of Table 7, we compare the mean for the years 1996-1997 (the initial years) with the mean for the years 20042005 (the final years).

[Table 7 around here]

In general, we can see that the percentage of variation in papers published under each topic before and after the SUA is low, with a maximum of $-5 \%$ in the case of financial analysis. Excluding non-accounting papers, topics such as financial reporting, accounting-method choice, financial analysis, and public sector and social accounting continue to dominate the research field even after the new regulation, although in the main areas, the only increase in number of papers $(3 \%)$ is in the financial reporting category. These results mirror the evolution registered in successive editions of European Accounting Association conferences, and coincide with the fact that it is also a popular topic in US journals. Despite variations, we cannot confirm hypothesis $\mathrm{H}_{6}$, because except in the abovementioned case, there was a decrease in the number 
of papers on the mainstream research topics. In fact, there is an increase in the number of papers investigating new or non-mainstream subjects; for instance, topics popular in US empirical journals, but not in Spain, such as capital markets and auditing, have increased, and also less substantial topics such as accounting education and history, while papers on topics like tax and the public sector have declined in number. The reduction in financial analysis—an important topic in US empirical journals - may also be due to difficulties in accurately classifying areas.

This trend toward higher diversity is the opposite of the effects of rankings in other places, where researchers seeking to publish tend to focus on mainstream and well-established topics. (Tuttle and Dillard (2007) qualify this trend as "a dramatic reduction in the diversity of research topics".) It appears that researchers try to find niche areas of study that enhance their publication opportunities. Another possible explanation could be that there was a high concentration of topics in Spain, and the only way to achieve a competitive advantage was to diversify. This fact is particularly evident in the case of non-accounting topics, an important category showing a 3\% increase.

Overall, topics seem to have moved toward empirical areas (see, for example, financial reporting) in detriment to areas such as accounting theory or taxation, which are mostly addressed in professional papers, although there are no significant statistics.

Table 7 presents information on the percentage of academic papers by topic, number of papers in non-Spanish journals, and papers with empirical methods. We present the mean values for each of these characteristics during the initial and final years of the study. The most important change is in the auditing area: $12 \%$ of all the papers on the subject of auditing were published in academic journals in the years 1996-1997. However, in the years 2003-2004 84\% of the total papers on auditing were published in academic journals. The $72 \%$ increase in papers published in academic journals reflects the change in the target journal preferences of academics in the field of accounting. 
Excluding accounting theory and capital markets, which show negative growth, the percentage of academic papers on all other topics has risen. In some cases, the increase is very significant (as in the case of auditing). In sum, it appears that, with specific topics, it was easier to switch from a professional to an academic style, although in some cases this switch occurred very slowly (e.g., auditing, taxation, and studies on accounting methods). The year of significant differences for most topic categories seems to be 2003, two years after the SUA.

We can also compare topics by the percentage of papers published in non-Spanish journals. Although there is an increase in papers published across topics, the initial increase was nonsignificant. The proportion of the increase varies among topics, with notably higher values for topics such as auditing, public sector, international accounting, and others. Although statistically non-significant, 2004 seems to be the first year in which increases were seen in papers on four topic categories.

Finally, a comparison of topics by research methods (empirical vs. non-empirical) revealed no increase in the percentage of empirical studies except in the case of two topics: taxation and accounting theory. Topics exhibiting a clear shift toward academic journals and an international reach generally had a higher percentage of papers employing empirical methods: nonaccounting, auditing, management, and others. In the last column of Table 7, we indicate the direction of change in research methods for the topics in which a trend was discernible. Empirical studies usually imply the use of statistical methods; however, some papers on public sector accounting, management, and others feature alternative empirical techniques such as case and survey methodologies.

\section{CONCLUSIONS AND IMPLICATIONS}

In this paper we have analyzed articles authored by Spanish accounting academics between 1996 and 2005 to assess the impact of a change in the Spanish university regulations. Results indicate that the new rules led academics to switch from publishing professional papers to 
academic papers, putting the relationship between accounting research and professional practice in jeopardy. Of course, this result is naturally in line with the expectations and the new requirements imposed by the regulation, which exclusively favors articles published in indexed academic journals. However, it has important implications since it has led to the distancing of new academics from practitioners. The finding shows a decline in the papers published in professional journals, which are not indexed and, therefore, are not considered in promotion processes.

Beyond institutional forces, personal preferences can also influence the choice to publish in academic and indexed journals, showing that researchers are not completely subjected to coercive pressures. In fact, before the SUA papers were addressed to both professional and academic journals, even in the absence of strong incentives to publish in the latter category. But we can observe that in the Spanish university system, incentives defined in the scheme rules exert coercive pressures that are a powerful mechanism to produce more academic research, and also change research methods, but not study areas, which can follow more personal preferences.

The new regulation has also led to significant changes in the methods researchers use. In the time period considered, owing to mimetic pressures authors moved away from non-empirical toward empirical methods in a bid to meet the requirements of academic journals as shown by our results. In 1996, most papers were oriented toward professional journals (55\%, without significant differences from academic papers), were mainly published in Spanish journals (90\%), and employed non-empirical research methods (74\%). In line with our research hypothesis, the new institutional forces (coercive, mimetic, and normative) influenced academics' behavior and, as a result, in 2005 scientific production of accounting papers presented quite a different picture: the number of papers with an academic orientation increased (70\%), their publication in non-Spanish journals also increased (15\%), as did the preference for empirical methods (50\%). Moreover, empirical research techniques, especially statistical ones, proved to be more successful than other methods in facilitating the shift toward academic 
journals. As the trend gained popularity, mimetic and normative mechanisms increased the level of isomorphism influencing the research of Spanish accounting academics.

Overall, Spanish researchers have changed their research methods, but not their areas of study. Some fields of study have been more conducive to a change in methods, achieving an academic orientation and adapting to performance-based incentives within a relatively short period of time, between one and two years. Thus, institutional pressures (coercive, mimetic and normative) play a decisive role in Spanish academia. While coercive mechanisms are significant in certain processes (which connects our results with those presented in Decramer et al. 2012), at other times mimetic forces appear to dominate.

The total number of published papers grew steadily from 1996 to 2003, but dropped in 2004 . Our data lead us to believe that many accounting academics are moving from quantity to quality (quality being defined here as a concept depending on the AWCR index) in scientific production, owing to the new requirements of university careers and research policies. This is an intrinsically good trend and reflects the favorable future potential of Spanish accounting academia. However, while the new regulation has been clearly positive for academic papers, it has some other unexpected and undesirable side effects. The most obvious of these is the drop in the number of active scholars, a trend that can be largely attributed to scholars' motivation. Indeed, many academics, after considering the requirements and compensations of continuing active research, may have decided to give up their publishing hopes. The decision may have been reinforced by the demands to switch to modern research methods and the limited value of continuing to publish professional papers.

As well as the decline in the number of authors publishing papers, there has also been a significant reduction in the number of professional papers. Because the reduction in the number of professional articles is greater than that of authors, the productivity of authors writing professional articles (the ratio number of articles/number of authors) has also declined. This scenario can negatively affect the transmission of knowledge from university to professionals 
and put at risk the relationship between the academia and the practitioners. Although this inertia was not part of the legislator's objectives, it is a fallout of the SUA. This effect of the SUA in Spain has already been studied by García-Benau et al., (1996) and also highlighted by Montesinos (1998). Moreover, Hopwood (2008) suggests that these results coincide with the general situation in the field of accounting and that accounting research is internally focused toward researchers (Hopwood, 2007).

While our results suggest that the SUA may be the primary factor influencing publication patterns in Spain, there could also be other factors that might determine changes in the behavior of accounting academics, such as the rise of research assessments in many European countries over the last decades. This implies that there is an increasingly international market for academics who publish in international journals. In this sense, shifting publications to such journals may increase the academics' "marketability" in terms of mobility, salary improvements and promotion.

Our findings have several implications. First, and as already stated in prior literature, incentives can be used as a powerful tool to modify academics' behavior. By defining the targets to be achieved, legislators can elicit the desired behavior, and the results do not take long to appear. The problem, however, is that narrow objectives produce unexpected and, sometimes, undesirable outcomes because agents begin to suffer from tunnel vision by focusing their efforts on fulfilling only the explicit objective. And this brings a new dimension into the literature. In the case of Spain, the progressive estrangement of academics from practitioner journals has contributed to the distance between the profession and the academia. Thus, this undesirable effect of the new regulation is verified.

We have seen how accounting academics in Spain do not expend much effort on other lateral objectives that are not considered in the incentive scheme. These results therefore show a new perspective that has not previously been considered and that could lead regulators and administrators in Spain to rethink the incentives systems and the relationship between the 
academia and the profession. For instance, in our study of effects of the SUA, perhaps a more gradual scheme, defining a wider range of capabilities, could have helped universities improve their process of not only generating knowledge but also disseminating it to active professionals. Therefore, the change of orientation in academics' activity presented in this article is expected to have an important effect on the relationship between accounting research and professional practice. If we consider that accounting research should be close to practitioners, helping them to develop and improve their skills, our question is whether these changes in the accounting research requirements may endanger this relationship.

Beyond the accounting arena, our findings also have implications for the wider issue of alignment between the strategic objectives of the university system and the desired profile of the academic faculty. A recent debate put forward two opposing views of the university system. On the one hand, the university can be regarded as an isolated research center, investing no efforts whatsoever to establish commercial and economic links (Shane, 2004). On the other hand, the new paradigm defines universities as active centers of knowledge transfer to society (Jacob et al. 2003), giving rise to the phenomenon of university entrepreneurship (Clark, 1998; Etzkowitz et al., 2000; Etzkowitz, 2003). For a university that sees itself as the former, the ideal faculty profile is that of a teacher devoted to research. However, if the university system is to be modeled along the latter lines, the required profile would have to be extended to include multidisciplinary scholars, capable of guaranteeing a harmony between the creation of knowledge and its proper transfer. 


\section{NOTES}

${ }^{1}$ According to the new Spanish regulation, the quality of journals is determined by their presence in several internationally recognized indexes. Particularly, the regulation notes Science Citation Index, Social Science Citation Index, Econlit and Latindex, leaving the list open to other similar possibilities and without specifying any ranking in the indexes, although high quality papers can have a special consideration. While this view is an interesting and debatable issue in itself, it is far beyond our scope of discussion and therefore not addressed here.

${ }^{2}$ Research assessments have been very scantily used in the field of accounting and finance. From 1989 to 2005 , only $30 \%$ of scholars applied for voluntary assessment. Of those, only $27 \%$ received positive evaluations. In 2005, only 31 scholars in the field were evaluated, with a success rate of $65 \%$.

${ }^{3}$ Findings of a 2008 study commissioned by HEFCE (The Higher Education Funding Council for England) states that the RAE encouraged researchers to concentrate on publishing more papers, particularly in peer-reviewed journals.

${ }^{4}$ This database is freely accessible at the following URL: http://ec3.ugr.es/in-recs/. To our knowledge no Spanish accounting scholars published in English only during this period.

${ }^{5}$ The EAA taxonomy is more complete than Sundem's classification, because it identifies in great detail the numerous categories of financial accounting and does not consider "research method" and "professional papers" to be topics, as Sundem does.

${ }^{6}$ Although of course the categorization will not be completely free of bias.

${ }^{7}$ Publish or Perish is a free software program that retrieves and analyzes academic citations. It uses Google Scholar to obtain raw citations, then analyzes these and calculates a series of citation metrics. The webpage http://www.harzing.com/pop_gs.htm explains the advantages and limitations of using Publish or Perish as opposed to other databases, such as the Thomson ISI Web of Science. From the accounting point of view, the obvious advantage of Google Scholar over the ISI Web of Science as a source of information is that accounting journals are well represented in the former and extremely scarce in the latter.

${ }^{8}$ In this article we work with categorical variables (orientation, year, country and research area and method). Thus, a bi-variable analysis based on contingency tables and Pearson $\chi^{2}$ is the most appropriate statistical tool to apply. We could have employed a multivariate analysis, such as logistic or probit regression with article orientation (professional or academic) as the dependent variable; however, the innumerable independent variables and their interactions (e.g., interaction of year with area and empirical/non-empirical methods yields 260 variables: 10 years $\times 13$ areas $\times 2$ methods) with increasing multicollinearity would lead to problems that are difficult to manage. Even so, we have performed this analysis, but by only regressing the dependent variables parsimoniously: in the first case with years, in the second with research method, and finally with research areas. The findings are similar to those we obtained, although less significant.

${ }^{9}$ In a separate analysis, not included in Table 4, we found that changes between 2004 and the earlier years emerged as significant in the year 2004 for both deductive and statistical methods. 


\section{ACKNOWLEDGEMENTS}

This study was financially supported by the Spanish Department of Science and Innovation (Plan Nacional de Investigación Científica, 2010-2013, Code ECO 2010-18967). The authors thank M. Angeles Morales for assistance with data collection and database construction. They also thank Stefan Van Hemmen and David Urbano for their valuable comments. 


\section{REFERENCES}

AIDEA (2007) La classificazione delle riviste per la valutazione della ricerca economicoaziendale. Il Journal Rating delle riviste internazionali e il percorso di accreditamento delle riviste italiane. Gruppo di Studio ed Attenzione AIDEA, in "Valutazione e Misurazione delle Performance in Ambito Universitario", September.

Albu, C. and Albu, N. (2009) How to perform in the field of accounting research? The case of Romania, 2009 Annual Congress of the European Accounting Association, April, Tampere (Finland).

Bar-Ilan, J. (2008) Which h-index? A comparison of WoS, Scopus and Google Scholar, Scientometrics, 74(2), 257-271.

Bentley, P. J. and Kyvik, S. (2012) Academic work from a comparative perspective: a survey of faculty working time across 13 countries, Higher Education, 63, pp. 529-547.

Bihui, J. B. (2007) The AR-index: complementing the h-index, ISSI Newsletter, 3(1), pp. 6.

Bricker, R. (1989) An empirical investigation of the structure of accounting research, Journal of Accounting Research, 27(2), pp. 246-262.

Cheung, C. K. (2008) Audience matters: a study of how authors select educational journals, The Asia-Pacific Education Researcher, 17(2), pp. 191-201.

Chung, K. H., Pak, H. S. and Cox, R. A. K. (1992) Patterns of research output in the accounting literature- a study of the bibliometric distributions, Abacus, 28(2), pp. 168-185.

Clark, B. R. (1998) Creating Entrepreneurial Universities. Organisational pathways of transformation (New York: Pergamon IAU Pres).

Decramer, A., Smolders, C., Vanderstraeten, A. and Christiaens, J. (2012) The impact of Institutional Pressupres on Employee Performance Management Systems in Higher Education in the Low Countries, British Journal of Management, 23, pp. 88-103.

DiMaggio, P. J. and Powell, W. W. (1983) The iron cage revisited: institutional isomorphism and collective rationality in organizational fields, American Sociological Review, 48, pp. $147-160$.

DiMaggio, P. J. and Powell W. W. (1991) The New Institutionalism in Organizational Analysis (Chicago: University of Chicago Press).

Etherington, L. D. and Richardson, A. J. (1994) Institutional pressures on university accounting education in Canada, Contemporary Accounting Research (Special Education Research Issue), pp. 141-162.

Etzkowitz, H. (2003) Research groups as 'quasi-firms': the invention of the entrepreneurial university, Research Policy, 32, pp. 109-121.

Etzkowitz, H., Webster, A., Gebhardt, C. and Terra, B. (2000) The future of the university and the university of the future: evolution of the Ivory Tower to entrepreneurial paradigm, Research Policy, 29, pp. 313-330.

García-Benau, M. A. and Laínez-Gadea, J. A. (2004) Forever destined to be extras in a Broadway show? in Humphrey, C. and Lee, B. (eds). The Real Life Guide to Accounting Research (Elsevier. The Netherlands), pp. 73-94.

García-Benau, M. A., Gandía-Cabedo, J. L. and Vico-Martínez, A. (1996) Relación entre teoría y práctica contable: Un análisis de la situación en España, (Madrid. AECA). 
Gendron, Y. (2008) Constituting the academic performer: the spectre of superficiality and stagnation in academia, European Accounting Review, 17(1), pp. 97-127.

HEFCE (2008) Analysis of responses to HEFCE 2007/34, the research Excellence Framework consultation. Available in thttp://www.hefce.ac.uk/pubs/consult/outcomes/ref.pdf

Hopwood, A. (2007) Whither accounting research?, The Accounting Review, 82(5), pp. 13651374.

Hopwood, A. (2008) Changing pressures on the research process: on trying to research in an age when curiosity is not enough, European Accounting Review, 17(1), pp. 87-96.

Hussain, S (2012) Further Food for Thought on the ABS Guide. Accounting Education: an international journal, 21:1, pp 17-22.

Jacob, M., Lundqvist, M. and Hellsmark, H. (2003) Entrepreneurial transformation in the Swedish university system: the case of Chalmers University of Technology, Research Policy, 32, pp. 1555-1568.

Kyvik, S. (2003) Changing trends in publishing behaviour among university faculty, 1980-2000, Scientometrics, 58(1), pp. 35-48.

Lee, F. S. (2006) The research assessment exercise, the state and the dominance of mainstream economics in British universities, Cambridge Journal of Economics, 31, pp. 309-325.

Leicht, K. T. and Fennell, M. L. (2008) Who staffs the US leaning tower? Organisational change and diversity, Equal Opportunities International, 27(1), pp. 88-106.

Larrinaga, C. (2005) Producción científica en contabilidad: el caso de España (1992-2002), Revista Española de Financiación y Contabilidad, 125, pp. 363-394.

Loft, A., Jorissen, A. and Walton, P. (2002) From newsletter to academic journal: creating the European Accounting Review, The European Accounting Review, 11(1), pp. 43-75.

Luukkonen, T. (1992) Is scientists' publishing behaviour reward-seeking?, Scientometrics, 24(2), pp. 297-319.

Merino, B. D. (1993) An analysis of the development of accounting knowledge: a pragmatic approach, Accounting Organizations and Society, 18(2-3), pp. 163-185.

Meyer, J. W. and Scott, W. R. (1983) Organizational Environments: Ritual and Rationality, (Beverly Hills, CA: Sage).

Meyer, J. W. and Rowan, B. (1977) Institutionalized organizations: formal structure as myth and ceremony, American Journal of Sociology, 83, pp. 340-63.

Mizruchi, M. S. and Fein L. C. (1999) The social construction of organizational knowledge: a study of the uses of coercive, mimetic, and normative isomorphism, Administrative Science Quarterly, 44, pp. 653-683.

Moed, H. E. (2008) UK research assessment exercise: informed judgments on research quality or quantity?, Scientometrics, 74(1), pp. 153-161.

Moizer, P. (2009) Publishing in accounting journals: a fair game?, Accounting, Organizations and Society, 34, pp. 285-304.

Montesinos, V. (1998) Accounting and Business Economics in Spain, European Accounting Review, 7(3), pp. 358-380.

Moya, S. and Prior, D. (2008) ¿Quién publica en las revistas españolas de contabilidad? Análisis bibliométrico del periodo 1996-2005, Revista Española de Financiación y Contabilidad, 37(138), pp. 353-374. 
Napier, C. J. (2006) Accounts of change: 30 years of historical accounting research, Accounting Organizations and Society, 31(4-5), pp. 445-506.

Nedeva, M., Boden, R. and Nugroho, Y. (2012) Rank and file: managing individual performance in university research, Higher Education Policy, 25, 335-360.

Newman, M. (2009) Liverpool may drop subjects ranked below 4* in RAE, (Times Higher Education. UK).

North, D. (1990) Institutions, Institutional Change and Economic Performanc, (New York: Cambridge University Press).

Orr, D. (2004) Research assessment as an instrument for steering higher education: a comparative study, Journal of Higher Education Policy and Management, 26(3), pp. 345362.

Oster, S. M., and Hamermesh, D. S. (1998). Aging and productivity among economists. Review of Economics and Statistics, 80(1), pp. 154-156.

Ray, P. (2008) Measuring research quality: the United Kingdom government's research assessment exercise, European Journal of Information Systems, 17(4), pp. 324-329.

Reiter, S. A. and Williams, P. F. (2002) The structure and progressivity of accounting research: the crisis in the academy revisited, Accounting Organizations and Society, 27(6), pp. 575607.

Rosenstreich, D. and Wooliscroft, B. (2009) Measuring the impact of accounting journals using Google Scholar and the g-index, The British Accounting Review, 41, pp. 227-239.

Sangster, A. (2011) The ABS Journal Quality Guide: a personal view, Accounting Education: an international journal, 20(6), pp. 575-580.

Shane, S. (2004) Academic Entrepreneurship. University Spin-offs and Wealth Creation, (UK: Edward Elgar Publishing).

Shore, C. and Wright, S. (2000) Coercive accountability: The rise of audit culture in higher education. In, M. Strathern (ed.), Audit Cultures, London: Routledge, pp. 57-89.

Sundem, G. L. (1987) Overview of four years of submissions to the Accounting Review, The Accounting Review, 62(1), pp. 191-202.

Tuttle, B. and Dillard, J. (2007) Beyond Competition: Institutional Isomorphism in U.S. Accounting Research, Accounting Horizons, 21(4), pp. 387-409.

Walter, G., Bloch, S., Hunt, G. and Fisher, K. (2003) Counting on citations: a flawed way to measure quality, Medical Journal of Australia, 178(6), pp. 280-281.

Watts, R. L., and J. L. Zimmerman. 1978. Towards a positive theory of the determination of accounting standards. The Accounting Review 53 (January): 112-134. 
Table 1. Taxonomy of accounting topics and their description

\begin{tabular}{|c|c|c|c|}
\hline $\begin{array}{l}\text { Topics defined by Sundem } \\
\text { (1987) }\end{array}$ & Topics in EAA (31st Annual Congress) & Topics defined in this article & Description of the topic \\
\hline Audit & Auditing & (AUD) Auditing & Papers on auditing \\
\hline \multirow{4}{*}{ Financial Accounting } & Financial Accounting (capital markets) & (CMA) Financial Accounting (capital markets) & $\begin{array}{l}\text { Papers related to the effect on the market of prices of some } \\
\text { accounting aspects (disclosures, business valuation, etc.) }\end{array}$ \\
\hline & Financial Statement Analysis & (FAN) Financial Statement Analysis & $\begin{array}{l}\text { Work on analysis. Includes efficiency papers, such as DEA, and } \\
\text { insolvency papers. Also includes papers on distribution of } \\
\text { dividends and consolidation (based on annual accounts) }\end{array}$ \\
\hline & \multirow{2}{*}{$\begin{array}{l}\text { Financial Reporting (choice of accounting } \\
\text { method) }\end{array}$} & (FRG) Financial Reporting & Papers about disclosure practices and their reasons \\
\hline & & $\begin{array}{rrrr}(\text { AMC) Financial } & \text { Accounting } & \text { (choice of } \\
\text { accounting method) } & & & \\
\end{array}$ & $\begin{array}{l}\text { Papers related to accounting policies, conservatism, or accounting } \\
\text { manipulation. Also includes accountancy sector studies }\end{array}$ \\
\hline International Accounting & International Financial Accounting & (INA) International Financial Accounting & Country comparisons or non-Spanish accounting papers \\
\hline Managerial Accounting & Management Accounting & (MAN) Management Accounting & $\begin{array}{l}\text { Papers on management accounting, internal reporting, contractual } \\
\text { relationships (agency). Also includes DEA with internal data }\end{array}$ \\
\hline Taxation & Taxation and Accounting & (TAX) Taxation and Accounting & Papers on tax \\
\hline \multirow[t]{6}{*}{ Non-profit/Government } & $\begin{array}{l}\text { Public Sector and Not-for-profit Accounting } \\
\text { Social and Environmental Accounting }\end{array}$ & $\begin{array}{l}\text { (PSA) Public Sector, Not-for-profit Accounting } \\
\text { and Social and Environmental Accounting }\end{array}$ & $\begin{array}{l}\text { Studies of the public sector and papers focused on corporate social } \\
\text { responsibility or environmental and social accounting }\end{array}$ \\
\hline & Accounting Education & \multirow[b]{2}{*}{ (AEH) Accounting Education and History } & \multirow{2}{*}{$\begin{array}{l}\text { Papers related to education in accounting, including surveys of } \\
\text { teachers and bibliometric analysis, and papers on accounting } \\
\text { history }\end{array}$} \\
\hline & Accounting History & & \\
\hline & Accounting Theory & (ATH) Accounting Theory & $\begin{array}{l}\text { Theoretical papers. Can be analytical but not empirical. Can also } \\
\text { be professional but not devoted to developing a specific } \\
\text { accounting standard }\end{array}$ \\
\hline & $\begin{array}{l}\text { Analytical Research in Accounting and } \\
\text { Auditing }\end{array}$ & \multirow{7}{*}{ (OTH) Others } & \multirow{7}{*}{ Other papers on accounting topics } \\
\hline & Critical Perspectives on Accounting & & \\
\hline \multirow[t]{3}{*}{ Information Systems } & Accounting and Information Systems & & \\
\hline & Corporate Governance (and accounting) & & \\
\hline & Organizational and Behavioral Aspects & & \\
\hline Not defined & \multirow{2}{*}{ Miscellaneous } & & \\
\hline Others & & & \\
\hline \multicolumn{4}{|l|}{ Professional } \\
\hline \multicolumn{4}{|l|}{ Research Methods } \\
\hline- & - & (NAC) Non-accounting & Papers not related to accounting \\
\hline
\end{tabular}


Table 2. Taxonomy of research methods

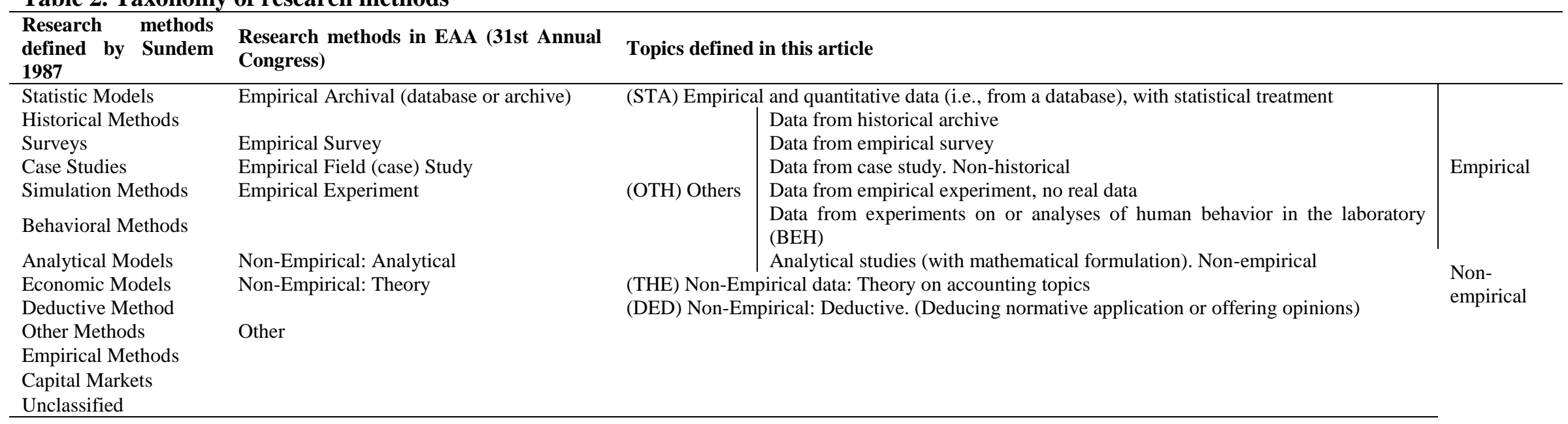


Table 3. Papers by orientation, country, and years

Panel A. Number of papers by orientation (academic or professional) and years

\begin{tabular}{lc|ccccccccccc} 
& & $\mathbf{1 9 9 6}$ & $\mathbf{1 9 9 7}$ & $\mathbf{1 9 9 8}$ & $\mathbf{1 9 9 9}$ & $\mathbf{2 0 0 0}$ & $\mathbf{2 0 0 1}$ & $\mathbf{2 0 0 2}$ & $\mathbf{2 0 0 3}$ & $\mathbf{2 0 0 4}$ & $\mathbf{2 0 0 5}$ & Total \\
\hline ACADEMIC & $\#$ & 45 & 45 & 33 & 67 & 50 & 58 & 75 & 115 & 81 & 74 & 643 \\
& $\%$ & $45 \%$ & $47 \%$ & $37 \%$ & $45 \%$ & $50 \%$ & $38 \%$ & $48 \%$ & $66 \%$ & $68 \%$ & $70 \%$ & $52 \%$ \\
PROFESSIONAL & $\#$ & 55 & 50 & 57 & 83 & 51 & 96 & 80 & 60 & 39 & 31 & 602 \\
& $\%$ & $55 \%$ & $53 \%$ & $63 \%$ & $55 \%$ & $50 \%$ & $62 \%$ & $52 \%$ & $34 \%$ & $33 \%$ & $30 \%$ & $48 \%$ \\
TOTAL & $\#$ & 100 & 95 & 90 & 150 & 101 & 154 & 155 & 175 & 120 & 105 & 1,245
\end{tabular}

Pearson $\chi^{2}=67.2 * * *$

$* *$ Significant at the 0.05 level (p-value $<0.05$ ).

***:Significant at the 0.01 level ( $\mathrm{p}$-value $<0.01$ ).

Panel B. Significant values of Pearson $\chi^{2}$ for differences in number of papers (academic and professional) between the indicated years (non-significant years omitted).

\begin{tabular}{llll}
\hline & $\mathbf{2 0 0 3}$ & $\mathbf{2 0 0 4}$ & $\mathbf{2 0 0 5}$ \\
\hline $\mathbf{1 9 9 6}$ & $11.2 * * *$ & $11.2 * * *$ & $13.6 * * *$ \\
$\mathbf{1 9 9 7}$ & $8.5 * * *$ & $8.8 * * *$ & $11.1 * * *$ \\
$\mathbf{1 9 9 8}$ & $20.3 * * *$ & $19.7 * * *$ & $23.3 * * *$ \\
$\mathbf{1 9 9 9}$ & $14.5 * * *$ & $14.0 * * *$ & $16.6 * * *$ \\
\hline $\mathbf{2 0 0 0}$ & $7.0 * * *$ & $7.4 * * *$ & $9.4 * * *$ \\
$\mathbf{2 0 0 1}$ & $25.8 * * *$ & $24.0 * * *$ & $20.9 * * *$ \\
$\mathbf{2 0 0 2}$ & $10.1 * * *$ & $10.1 * * *$ & $12.4 * * *$ \\
Significant at the 0.05 level (p-value $<0.05)$. \\
Significant at the 0.01 level (p-value $<0.01)$.
\end{tabular}

Panel C. Percentage of papers in Spanish and non-Spanish journals by year.

\begin{tabular}{l|ccccccccccc} 
& $\mathbf{1 9 9 6}$ & $\mathbf{1 9 9 7}$ & $\mathbf{1 9 9 8}$ & $\mathbf{1 9 9 9}$ & $\mathbf{2 0 0 0}$ & $\mathbf{2 0 0 1}$ & $\mathbf{2 0 0 2}$ & $\mathbf{2 0 0 3}$ & $\mathbf{2 0 0 4}$ & $\mathbf{2 0 0 5}$ & Total \\
\hline Spanish & $98 \%$ & $96 \%$ & $96 \%$ & $94 \%$ & $95 \%$ & $94 \%$ & $90 \%$ & $91 \%$ & $86 \%$ & $85 \%$ & $92 \%$ \\
Non- & $2 \%$ & $4 \%$ & $4 \%$ & $6 \%$ & $5 \%$ & $6 \%$ & $10 \%$ & $9 \%$ & $14 \%$ & $15 \%$ & $8 \%$ \\
Spanish & & & & & & & & & & & \\
Pearson $\chi^{2}=26.1 * * *$ \\
$* *$ Significant at the 0.05 level (p-value < 0.05 ).
\end{tabular}

Panel D. Significant values of Pearson $\chi^{2}$ for differences in number of papers in Spanish and non-Spanish journals between the indicated years (non-significant years omitted).

\begin{tabular}{lllll}
\hline & $\mathbf{2 0 0 2}$ & $\mathbf{2 0 0 3}$ & $\mathbf{2 0 0 4}$ & $\mathbf{2 0 0 5}$ \\
\hline 1996 & $6.4^{* *}$ & $4.7^{* *}$ & $10.2^{* * *}$ & $11.2^{* * *}$ \\
1997 & & & $5.9^{* *}$ & $6.7^{* * *}$ \\
1998 & & & $5.4^{* * *}$ & $6.1 * *$ \\
1999 & & & $5.1 * * *$ & $5.9^{* *}$ \\
\hline 2000 & & & $5.1^{* *}$ & $5.9^{* *}$ \\
2001 & & & $4.5^{* *}$ & $5.2^{* *}$ \\
\hline
\end{tabular}

$* *$ Significant at the 0.05 level ( $\mathrm{p}$-value $<0.05$ ).

$* * *$ Significant at the 0.01 level ( $\mathrm{p}$-value $<0.01)$. 
Table 4. Papers by author, impact and orientation

Panel A. Number of papers with age-weighted citation rate (AWCR) > 0. Quartile 1: lowest AWCR and quartile 4: highest AWCR.

\begin{tabular}{l|cccccccccc} 
& 1996 & 1997 & 1998 & 1999 & 2000 & 2001 & 2002 & 2003 & 2004 & 2005 \\
\hline Quartile 1 & 13 & 18 & 16 & 22 & 18 & 0 & 0 & 0 & 0 & 0 \\
Quartile 2 & 7 & 2 & 6 & 13 & 0 & 15 & 22 & 26 & 15 & 0 \\
Quartile 3 & 10 & 1 & 4 & 12 & 15 & 12 & 10 & 11 & 8 & 10 \\
Quartile 4 & 4 & 2 & 5 & 9 & 7 & 14 & 12 & 24 & 14 & 16
\end{tabular}

Panel B. Descriptives of papers for periods 2000-2002 and 2003-2005

\begin{tabular}{l|cc} 
& $2000-2002$ & $2003-2005$ \\
\hline Total papers with AWCR $>0$ & 125 & 124 \\
Total AWCR & 77 & 126 \\
AWCR/paper & 0,62 & 1,02 \\
& & \\
Number of academic papers & 183 & 269 \\
$\quad$ Authors & 141 & 200 \\
$\quad$ Paper/author & 1.30 & 1.35 \\
Number of professional papers & 227 & 131 \\
$\quad$ Authors & 174 & 116 \\
$\quad$ Paper/author & 1.30 & 1.13
\end{tabular}


Table 5: Papers by research methods and years

Panel A. Percentage of papers employing empirical and non-empirical methods by year (Total: 1,245 papers)

\begin{tabular}{llllllllllll} 
& $\mathbf{1 9 9 6}$ & $\mathbf{1 9 9 7}$ & $\mathbf{1 9 9 8}$ & $\mathbf{1 9 9 9}$ & $\mathbf{2 0 0 0}$ & $\mathbf{2 0 0 1}$ & $\mathbf{2 0 0 2}$ & $\mathbf{2 0 0 3}$ & $\mathbf{2 0 0 4}$ & $\mathbf{2 0 0 5}$ & Total \\
\hline EMPIRICAL & $26 \%$ & $33 \%$ & $29 \%$ & $32 \%$ & $38 \%$ & $37 \%$ & $35 \%$ & $43 \%$ & $50 \%$ & $50 \%$ & $38 \%$ \\
NON-EMP. & $74 \%$ & $67 \%$ & $71 \%$ & $68 \%$ & $62 \%$ & $63 \%$ & $65 \%$ & $57 \%$ & $50 \%$ & $50 \%$ & $62 \%$ \\
\hline
\end{tabular}

Pearson $\chi^{2}=29.7 * * *$

**Significant at the 0.05 level (p-value $<0.05)$.

$* * *$ Significant at the 0.01 level (p-value $<0.01)$.

Panel B. Significant values of Pearson $\chi^{2}$ for differences in number of papers (with empirical and nonempirical methods) for each pair of indicated years (non-significant years omitted).

\begin{tabular}{lccc}
\multicolumn{4}{c}{ empirical methods) } \\
\hline $\mathbf{2 0 0 3}$ & $\mathbf{2 0 0 4}$ & $\mathbf{2 0 0 5}$ \\
\hline $\mathbf{1 9 9 6}$ & $8.2 * * *$ & $13.2 * * *$ & $12.9 * * *$ \\
$\mathbf{1 9 9 7}$ & & $6.5 * *$ & $6.5 * *$ \\
$\mathbf{1 9 9 8}$ & $5.3 * *$ & $9.5 * * *$ & $9.4 * * *$ \\
\hline $\mathbf{1 9 9 9}$ & $4.5 * *$ & $9.0 * * *$ & $8.8 * * *$ \\
$\mathbf{2 0 0 1}$ & & $4.6 * *$ & $4.6 * *$ \\
$\mathbf{2 0 0 2}$ & & $5.8 * *$ & $5.8 * *$ \\
\hline
\end{tabular}

**Significant at the 0.05 level (p-value $<0.05)$.

$* * *$ Significant at the 0.01 level (p-value $<0.01)$.

Panel C. Distribution of papers by different research methods from 1996 to 2005 (THE: Theory; STA: Statistical; DED: Deductive; OTH: Others)

\begin{tabular}{lccccccccccc}
\hline & $\mathbf{1 9 9 6}$ & $\mathbf{1 9 9 7}$ & $\mathbf{1 9 9 8}$ & $\mathbf{1 9 9 9}$ & $\mathbf{2 0 0 0}$ & $\mathbf{2 0 0 1}$ & $\mathbf{2 0 0 2}$ & $\mathbf{2 0 0 3}$ & $\mathbf{2 0 0 4}$ & $\mathbf{2 0 0 5}$ & Total \\
\hline STA & $21 \%$ & $22 \%$ & $22 \%$ & $21 \%$ & $32 \%$ & $27 \%$ & $25 \%$ & $36 \%$ & $39 \%$ & $31 \%$ & $28 \%$ \\
OTH & $5 \%$ & $11 \%$ & $7 \%$ & $12 \%$ & $6 \%$ & $11 \%$ & $12 \%$ & $7 \%$ & $13 \%$ & $21 \%$ & $11 \%$ \\
\hline THE & $49 \%$ & $41 \%$ & $46 \%$ & $42 \%$ & $38 \%$ & $40 \%$ & $51 \%$ & $39 \%$ & $38 \%$ & $30 \%$ & $41 \%$ \\
DED & $25 \%$ & $26 \%$ & $26 \%$ & $25 \%$ & $25 \%$ & $22 \%$ & $13 \%$ & $18 \%$ & $9 \%$ & $17 \%$ & $20 \%$
\end{tabular}

Pearson $\chi^{2}=66.1 * * *$

**Significant at the 0.05 level (p-value $<0.05$ ). $* * *$ Significant at the 0.01 level (p-value $<0.01)$.

Panel D. Significant values of Pearson $\chi^{2}$ for differences in number of papers (with different research methods) between the indicated years (years with non-significant $\chi^{2}$ values omitted).

\begin{tabular}{lcccc}
\hline & $\mathbf{2 0 0 2}$ & $\mathbf{2 0 0 3}$ & $\mathbf{2 0 0 4}$ & $\mathbf{2 0 0 5}$ \\
\hline 1996 & $8.3^{* *}$ & $8.4 * *$ & $19.6 * * *$ & $18.0 * * *$ \\
1997 & & & $14.6 * *$ & $8.5 * *$ \\
1998 & & & $16.0 * *$ & $13.0 * * *$ \\
1999 & & $9.8 * *$ & $16.6 * * *$ & $9.4 * *$ \\
\hline 2000 & $10.5 * *$ & & $12.0 * * *$ & $10.7 * *$ \\
2001 & & & $10.1 * *$ & \\
2002 & - & $9.0 * *$ & $8.1 * *$ & $11.6 * * *$ \\
2003 & - & & & $11.3 * * *$ \\
\hline
\end{tabular}

**Significant at the 0.05 level (p-value $<0.05)$

$* * *$ Significant at the 0.01 level (p-value $<0.01$ ). 
Table 6: Papers by orientation, research methods and years

\begin{tabular}{|c|c|c|c|c|c|c|c|c|c|c|c|}
\hline & 1996 & 1997 & 1998 & 1999 & 2000 & 2001 & 2002 & 2003 & 2004 & 2005 & Total \\
\hline Academic (\#) & 45 & 45 & 33 & 67 & 50 & 58 & 75 & 115 & 81 & 74 & 643 \\
\hline Empirical (\% of academic) & $49 \%$ & $58 \%$ & $64 \%$ & $60 \%$ & $64 \%$ & $62 \%$ & $60 \%$ & $51 \%$ & $69 \%$ & $73 \%$ & $61 \%$ \\
\hline STA (\% of empirical) & $77 \%$ & $65 \%$ & $81 \%$ & $73 \%$ & $81 \%$ & $67 \%$ & $64 \%$ & $88 \%$ & $77 \%$ & $61 \%$ & $73 \%$ \\
\hline OTH (\% of empirical) & $23 \%$ & $35 \%$ & $19 \%$ & $28 \%$ & $19 \%$ & $33 \%$ & $36 \%$ & $12 \%$ & $23 \%$ & $39 \%$ & $27 \%$ \\
\hline Non empirical ( $\%$ of academic) & $51 \%$ & $42 \%$ & $36 \%$ & $40 \%$ & $36 \%$ & $38 \%$ & $40 \%$ & $49 \%$ & $31 \%$ & $27 \%$ & $39 \%$ \\
\hline THE (\% of non-empirical) & $74 \%$ & $74 \%$ & $92 \%$ & $85 \%$ & $72 \%$ & $91 \%$ & $87 \%$ & $62 \%$ & $88 \%$ & $75 \%$ & $78 \%$ \\
\hline Professional (\#) & 55 & 50 & 57 & 83 & 51 & 96 & 80 & 60 & 39 & 31 & 602 \\
\hline Empirical (\% of professional) & $7 \%$ & $10 \%$ & $9 \%$ & $12 \%$ & $12 \%$ & $24 \%$ & $14 \%$ & $28 \%$ & $18 \%$ & $3 \%$ & $15 \%$ \\
\hline STA (\% of empirical) & $100 \%$ & $80 \%$ & $60 \%$ & $30 \%$ & $100 \%$ & $78 \%$ & $82 \%$ & $65 \%$ & $57 \%$ & $0 \%$ & $70 \%$ \\
\hline OTH (\% of empirical) & $0 \%$ & $20 \%$ & $40 \%$ & $70 \%$ & $0 \%$ & $22 \%$ & $18 \%$ & $35 \%$ & $43 \%$ & $100 \%$ & $30 \%$ \\
\hline Non empirical (\% of professional) & $93 \%$ & $90 \%$ & $91 \%$ & $88 \%$ & $88 \%$ & $76 \%$ & $86 \%$ & $72 \%$ & $82 \%$ & $97 \%$ & $85 \%$ \\
\hline THE (\% of non-empirical) & $63 \%$ & $56 \%$ & $58 \%$ & $55 \%$ & $56 \%$ & $56 \%$ & $77 \%$ & $77 \%$ & $75 \%$ & $57 \%$ & $62 \%$ \\
\hline
\end{tabular}


Table 7. Relationships and trends involving topics, article orientation, country of publication, and research methodology

\begin{tabular}{|c|c|c|c|c|c|c|c|c|c|}
\hline \multirow[b]{2}{*}{ Area } & \multicolumn{2}{|c|}{$\%$ papers } & \multicolumn{2}{|c|}{$\%$ academic papers } & \multicolumn{2}{|c|}{$\begin{array}{c}\% \text { papers in non-Spanish } \\
\text { journals }\end{array}$} & \multicolumn{2}{|c|}{$\begin{array}{c}\% \text { papers with empirical } \\
\text { methods }\end{array}$} & \multirow[b]{2}{*}{$\begin{array}{l}\text { Direction of research } \\
\text { method change }\end{array}$} \\
\hline & $\begin{array}{l}\text { Mean 1996- } \\
1997\end{array}$ & $\begin{array}{l}\text { Mean 2004- } \\
2005\end{array}$ & $\begin{array}{l}\text { Mean 1996- } \\
1997\end{array}$ & $\begin{array}{l}\text { Mean 2004- } \\
2005\end{array}$ & $\begin{array}{l}\text { Mean 1996- } \\
1997\end{array}$ & $\begin{array}{l}\text { Mean 2004- } \\
2005\end{array}$ & $\begin{array}{l}\text { Mean 1996- } \\
1997\end{array}$ & $\begin{array}{l}\text { Mean 2004- } \\
2005\end{array}$ & \\
\hline FRG & 10 & 13 & 45 & 86 & 0 & 10 & 20 & 45 & From THE to STA \\
\hline NAC & 10 & 13 & 55 & 93 & 5 & 8 & 31 & 44 & From THE to STA \\
\hline AMC & 13 & 11 & 15 & 46 & 0 & 12 & 7 & 24 & From DED to STA and THE \\
\hline FAN & 15 & 10 & 66 & 93 & 10 & 13 & 70 & 87 & Increase of STA method \\
\hline PSA & 12 & 10 & 61 & 76 & 4 & 27 & 24 & 44 & From THE to OTH and STA \\
\hline AEH & 5 & 8 & 80 & 87 & 10 & 16 & 80 & 87 & \\
\hline MAN & 8 & 8 & 25 & 55 & 0 & 11 & 6 & 40 & From THE to OTH \\
\hline AUD & 4 & 6 & 12 & 84 & 0 & 40 & 42 & 84 & From DED and THE to STA \\
\hline INA & 6 & 6 & 65 & 67 & 0 & 17 & 23 & 32 & From DED to STA \\
\hline OTH & 5 & 5 & 33 & 66 & 0 & 20 & 0 & 61 & From THE to OTH \\
\hline CMA & 2 & 4 & 83 & 62 & 0 & 12 & 83 & 62 & From STA to THE \\
\hline TAX & 6 & 4 & 7 & 47 & 0 & 0 & 14 & 10 & From DED to THE \\
\hline ATH & 4 & 3 & 57 & 50 & 0 & 0 & 0 & 0 & \\
\hline
\end{tabular}

Topics: FRG: Financial Reporting; NAC: Non-accounting papers; AMC: Choice of accounting method; FAN: Financial Analysis; PSA: Public Sector and Social Accounting; AEH: Accounting Education and History; MAN: Management; AUD: Auditing; INA: International Accounting; OTH: Other accounting papers; CMA: Capital markets; TAX: Taxation; ATH: Accounting Theory.

Research methods: THE: Theory; STA: Statistical; DED: Deductive; OTH: Others. 